\title{
O FATOR VERDE NO DESIGN THINKING CANVAS: USO DE CARTAS E HEURÍSTICAS PARA INFLUENCIAR DESIGNERS A TEREM IDEIAS SUSTENTÁVEIS
}

Clarissa Sóter, Dra

Universidade Federal de Pernambuco

André Neves, Dr.

Universidade Federal de Pernambuco

Ernesto Vilar, Dr.

Doutor, Universidade da Beira Interior, Portugal

Resumo: Este artigo descreve o experimento da tese de Doutorado em design no Brasil aplicado com estudantes de design em Portugal. Usamos a metodologia Design Thinking Canvas em dois projetos de produto e desenvolvemos cartas com o que chamamos de fator verde que foram adicionada à técnica de brainwrinting na Fase de Ideação, no intuito de induzir o surgimento de ideias sustentáveis por parte dos alunos. Também incluímos duas novas heurísticas de avaliação, na Fase de Solução, na tentativa de induzir os estudantes a escolherem como ideias finais aquelas sustentáveis. Como resultado tivemos, no projeto 1 , um percentual de $20 \%$ mais ideias sustentáveis no grupo que usou as cartas com fator verde disfarçadas e $26 \%$ no grupo que usou explicitamente as cartas verdes. No projeto 2 registramos um percentual de $40 \%$ de ideias sustentáveis, na Fase de Ideação, e posteriormente, na Fase de Solução, 100\% de ideias com preceitos socioambientais foram escolhidas como finais.

Palavras-chave: design, sustentabilidade, fator verde, cartas, heurísticas.

Abstract: This article describes the experiment of the PhD thesis in Design in Brazil applied with design students from Portugal. We use the Design Thinking Canvas methodology in two projects and developed cards with green factor concepts that were added to brainwrinting technique, in Ideation Phase, in order to induce the emergence of sustainable ideas from students. We have also included two new heuristics of evaluation, in the Solution phase, to induce students to choose sustainable ideas as final. As result we had in the project 1 a percentage of 20\% more sustainable ideas in the group that used the cards to disguise green factor and $26 \%$ in the group that used the green cards explicitly. In the project 2 we recorded a percentage of $40 \%$ of sustainable ideas in the Ideation phase, and later, in the Solution phase, $100 \%$ of ideas with socio environmental principles were chosen as final.

Keywords: design, sustainability, green factor, cards, heuristics. 


\section{INTRODUÇÃO}

Nosso projeto de pesquisa teve como objetivo principal avaliar se intervenções específicas na metodologia Design Thinking Canvas (DTC), com conceitos que chamamos de fator verde, seriam capazes de induzir o surgimento de mais ideias baseadas na sustentabilidade.

Para isso, primeiramente, estudamos a metodologia Design Thinking Canvas, alguns resultados das disciplinas onde a DTC foi aplicada e pesquisas de evolução e validação da metodologia no âmbito acadêmico como Credidio (2007); Alves (2011); Oliveira (2010); Bem (2014); Vargas (2015); Simona (2016).

Notamos que poucos projetos dos alunos apresentavam resposta à questão socioambiental, o que nos fez questionar se seria possível causar essas "influências positivas" intervindo na metodologia. Quanto as pesquisas acadêmicas percebemos terreno fértil para intervenções e experimentos com a DTC e, principalmente, que não houve testes no que diz respeito ao comportamento da metodologia frente aos desafios sustentáveis.

Consideramos também importante nos aprofundarmos em metodologias de design em geral. Então, estudamos 15 metodologias de design, comparando as tradicionais de autores como Bonsiepe (1984 apud Vasconcelos, 2009); Munari (1998 apud Vasconcelos, 2009); Lobach (2011); Burdek (2006) com outras de direcionamento sustentável de autores como Papanek (1984); Kazazian (2005); Manzini \& Vezzoli (2005); Walker (2006).

Observamos que há uma separação clara das questões ecológicas e sociais dos projetos regulares, como se valores sustentáveis fossem considerados uma especialidade no design e não um direcionamento normal do projeto, ou seja, para resultados sustentáveis seria necessário escolher esse caminho desde o início do projeto.

Aparentemente, seria possível interferir em qualquer metodologia de projeto tradicional para mais produtos sustentáveis, bastava ter essa escolha e nortear o projeto por esses valores. Acreditando nessa possibilidade, usamos a teoria da Walker (2006) para destacar o fato de que os designers devem perseguir os trabalhos com uma natureza sustentável, um processo que ele chama de exploratório, em favor da construção de uma base alternativa para a sua prática profissional e escolhemos iniciar essa exploração intervindo no nosso objeto de estudo, a metodologia DTC.

Por último, estudamos conceitos sustentáveis a partir de Veiga (2008); Boff (2014); Footprintnetwork (2014); Sachs (2015) e o fator verde nos produtos a partir de autores como Datschefski (2015); Motta (2007) e exemplos reais de produtos. Esses conceitos, que chamamos de fator verde, foram resumimos para orientar a construção das cartas verdes e heurísticas de avaliação, ponto chave da realização do experimento.

Nesse estudo, notamos que as características que tornam um produto verde estão enraizadas na escolha de materiais e processos de fabricação. Percebemos que não há "sorte" ou "acaso" no produto sustentável pois em todos os casos observados os produtos foram projetados para serem ecologicamente mais corretos e socialmente mais justos em todas ou em alguma fase do seu ciclo de vida.

No mesmo raciocínio, observamos que o principal fator que impulsiona um projeto sustentável é a consciência sobre o problema e, tendo como resultado final um artefato pensado desde a fase de concepção até sua disposição usuário. Nós também inferimos que este artefato deveria ser pensado para levar uma ação transformadora 
em termos sociais e ecológicos, propagando preceitos sustentáveis ao longo de sua configuração e muito além de seu uso.

Nosso trabalho enveredou por construir esse caminho, onde muitos desdobramentos poderiam ser feitos a partir do nosso experimento, o que tornaria, ainda mais importante, iniciar esse percurso.

A hipótese, então, seria intervir na DTC no intuito de influenciar designers a terem ideias mais sustentáveis quando eles não escolheram esse caminho, nem tiveram esse direcionamento solicitado pelas empresas.

Assim, preparamos o experimento que foi posteriormente aplicado com alunos do Curso de Design de Produto da Universidade da Beira Interior, Portugal, na disciplina Design do Produto III sob comando do Prof. Dr. Ernesto Vilar.

Dois projetos de produto, pertinentes à disciplina, foram usados para testar as intervenções do experimento, que foi inserido no contexto normal das aulas. Ambos os projetos foram considerados dentro do experimento e os dados obtidos compuseram as discussões sobre a hipótese da pesquisa, conclusão e desdobramentos.

\section{A DESIGN THINKING CANVAS}

A DTC é uma metodologia contemporânea criada para orientar equipes em atividades de projeto de artefatos com características inovadoras.

Foi construída nos últimos 10 anos, a partir de pesquisas desenvolvidas no Laboratório de Pesquisa em Jogos Digitais [GDRlab] dentro do Departamento de Design da UFPE (Brasil), sob a orientação do Prof. Dr. André Neves.

A DTC faz uso de um canvas similar ao que é utilizado na construção de modelos de negócios, em uma espécie de mapa descritivo formado por plataformas (decks ou tabuleiros) de informações. Como pode ser visto na figura 1 a seguir:

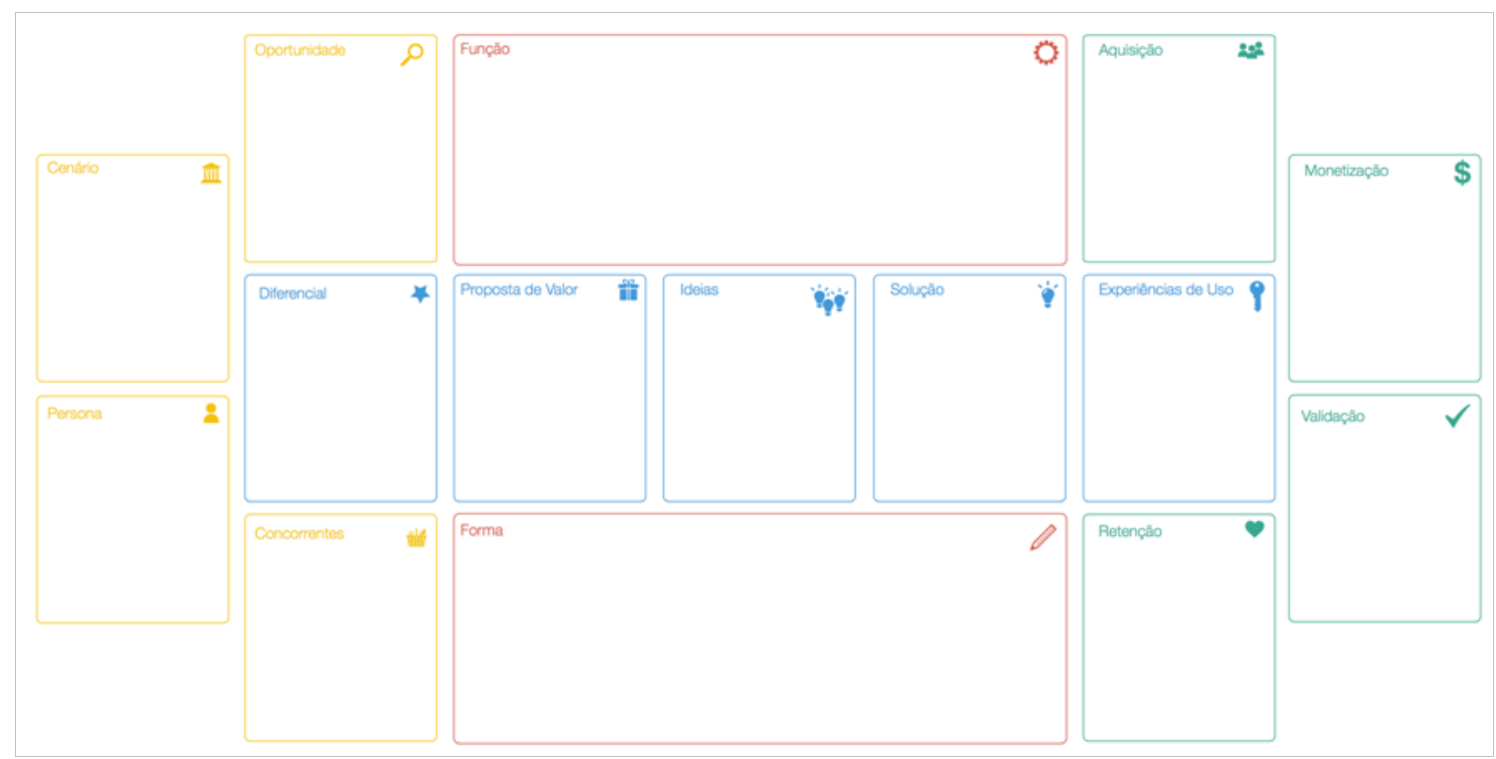

Figura 1 - Modelo de canvas da DTC.

Fonte: Neves (2014).

A DTC utiliza métodos e técnicas específicas do design para preencher as informações em cada plataforma e seu principal diferencial é o uso de cartas (tipo de baralho) como registro dessas atividades essenciais do processo, o que facilita o reuso 
de informações entre os projetos e as equipes. Essas cartas também servem para tornar o processo mais divertido, como um jogo (dai o termo gamificação).

O processo de design da DTC se organiza em quatro fases que acompanham o ciclo de vida do projeto: (1) Observação: onde se define o cenário de uso do produto, as características do público alvo (persona), se analisa possíveis oportunidades e os concorrentes; (2) Concepção: onde as ideias são geradas, avaliadas e selecionadas; (3) Configuração: onde são tomadas decisões quanto a função do produto, assim como sua forma (estética); (4) Publicação: onde ocorre o lançamento e a validação do projeto junto ao mercado consumidor. O que pode ser observado a seguir:

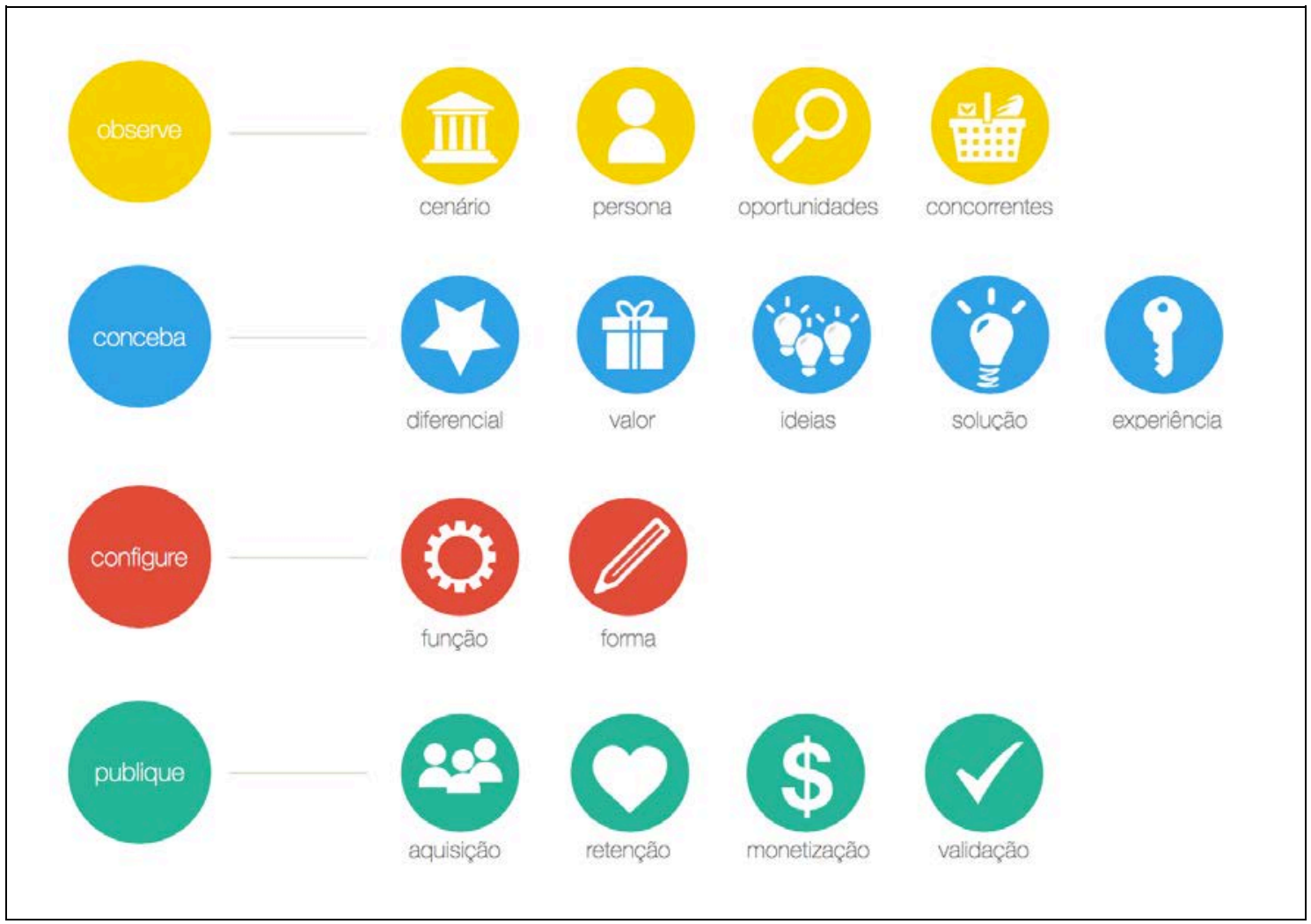

Figura 2 - Etapas do processo de design da DTC.

Fonte: Neves (2014).

\section{O EXPERIMENTO}

Na DTC a prática do design deve interpretar contextos através da observação, inferência e pesquisa. Para que esse contexto (num cenário ideal) fosse construído a partir de valores sustentáveis logo no início e esses valores deveriam guiar todo o processo de concepção, configuração, publicação, monitoramento e ajustes.

Dentro dessa lógica, a DTC se tornaria uma metodologia sustentável quando a zona de intervenção do fator verde no canvas e no uso das cartas de cada fase.

Porém, nossa hipótese foi intervir na DTC em busca de influenciar os designers a terem mais ideias sustentáveis, optamos por executar a Fase de Observação conforme direcionamento de Neves (2014) e realizar intervenções na Fase de Concepção, especificamente nas etapas de Ideação e Solução. Na Fase de Observação desenvolvemos: o CENÁRIO - onde, quando, quem e porque; a PERSONA e suas atividades; a carta de OPORTUNIDADE e quatro cartas com características dos CONCORRENTES. Na Fase de Concepção realizamos ajustes no DIFERENCIAL e 
executamos a IDEAÇÃO, a partir da técnica de brainwrinting e a SOLUÇÃO, por avaliação com heurísticas. Optamos, por eliminar a CURVA DE VALOR - por ser específica para design de artefato digital e a EXPERIÊNCIA, por necessitar de feedback do mercado após aprimoramento da ideia final (o que fugia da nossa hipótese).

Já os dois pontos de intervenção foram fundamentais no experimento pois serviram para testar a influência sobre as ideias dos estudantes. $O$ primeiro foi 0 desenvolvimento de uma nova categoria de 16 cartas com o fator verde que foram relacionadas às demais cartas na etapa de Ideação (figura 3):

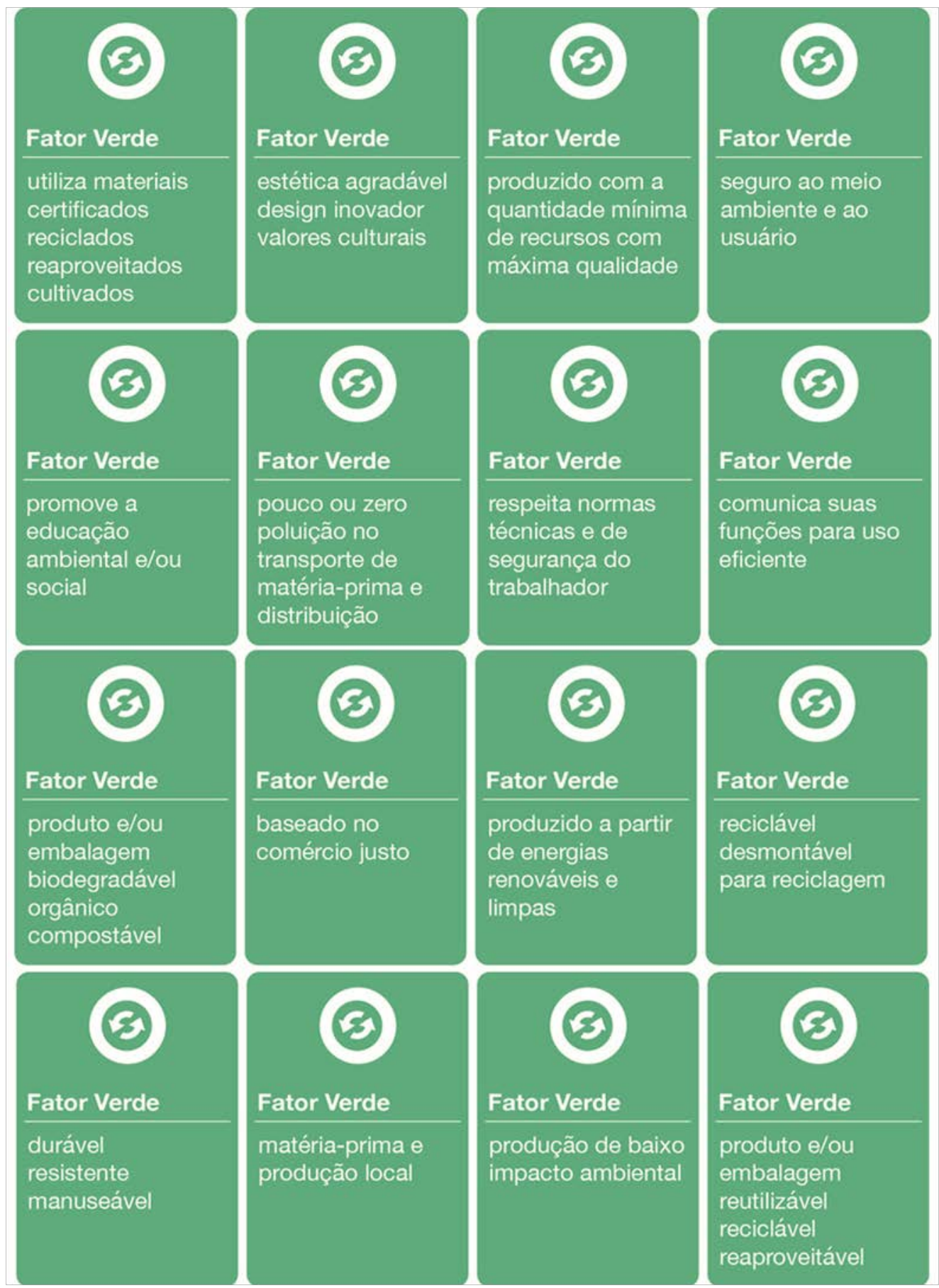

Figura 3 - Cartas com fator verde.

Fonte própria (2015). 
O segundo ponto foi a adição de duas novas heurísticas de avaliação na ficha de brainwrinting tradicionalmente usada na DTC. Duas novas perguntas uma relativa ao impacto ambiental da ideia e outra relativa ao impacto social (figura 4):
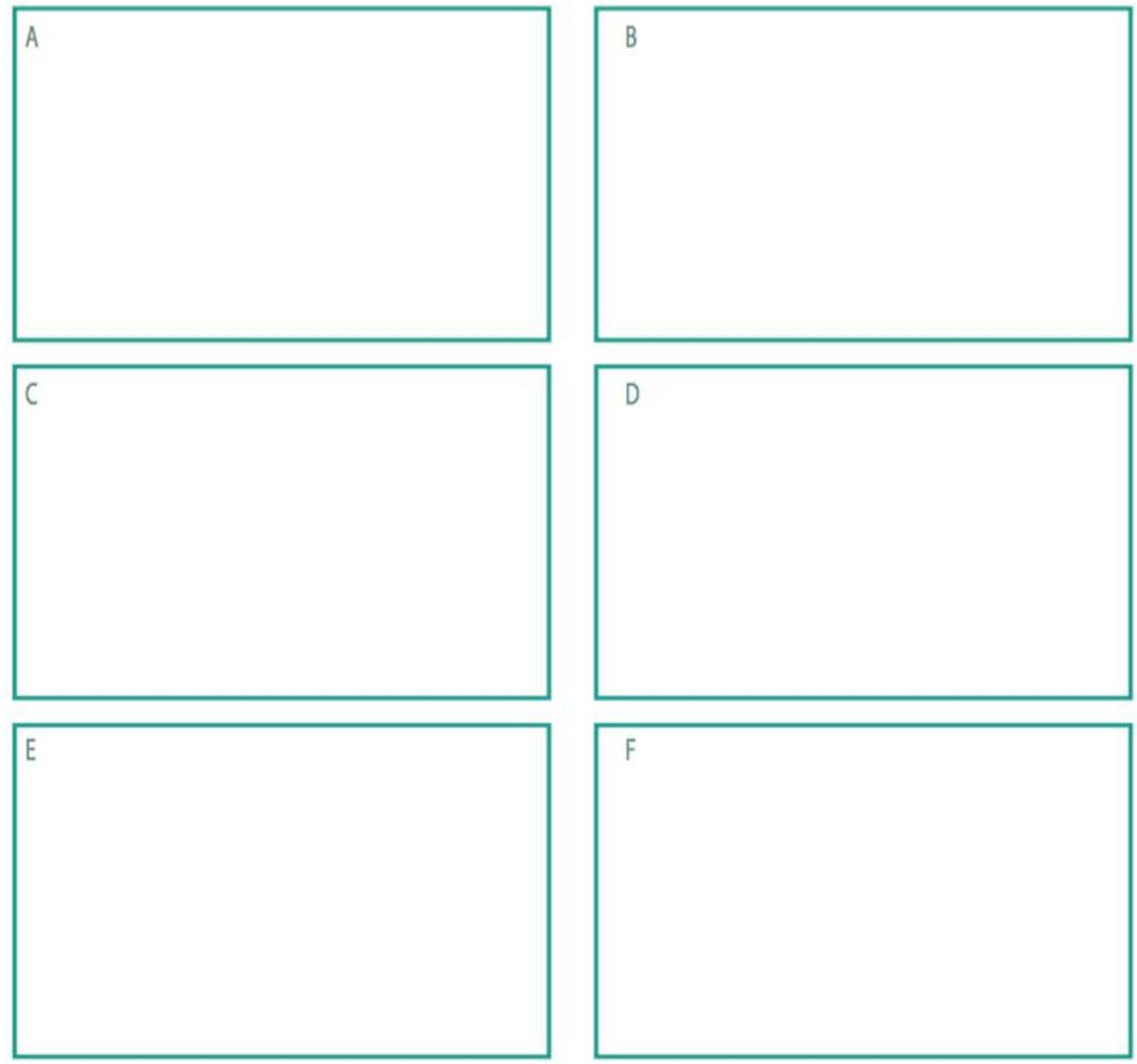

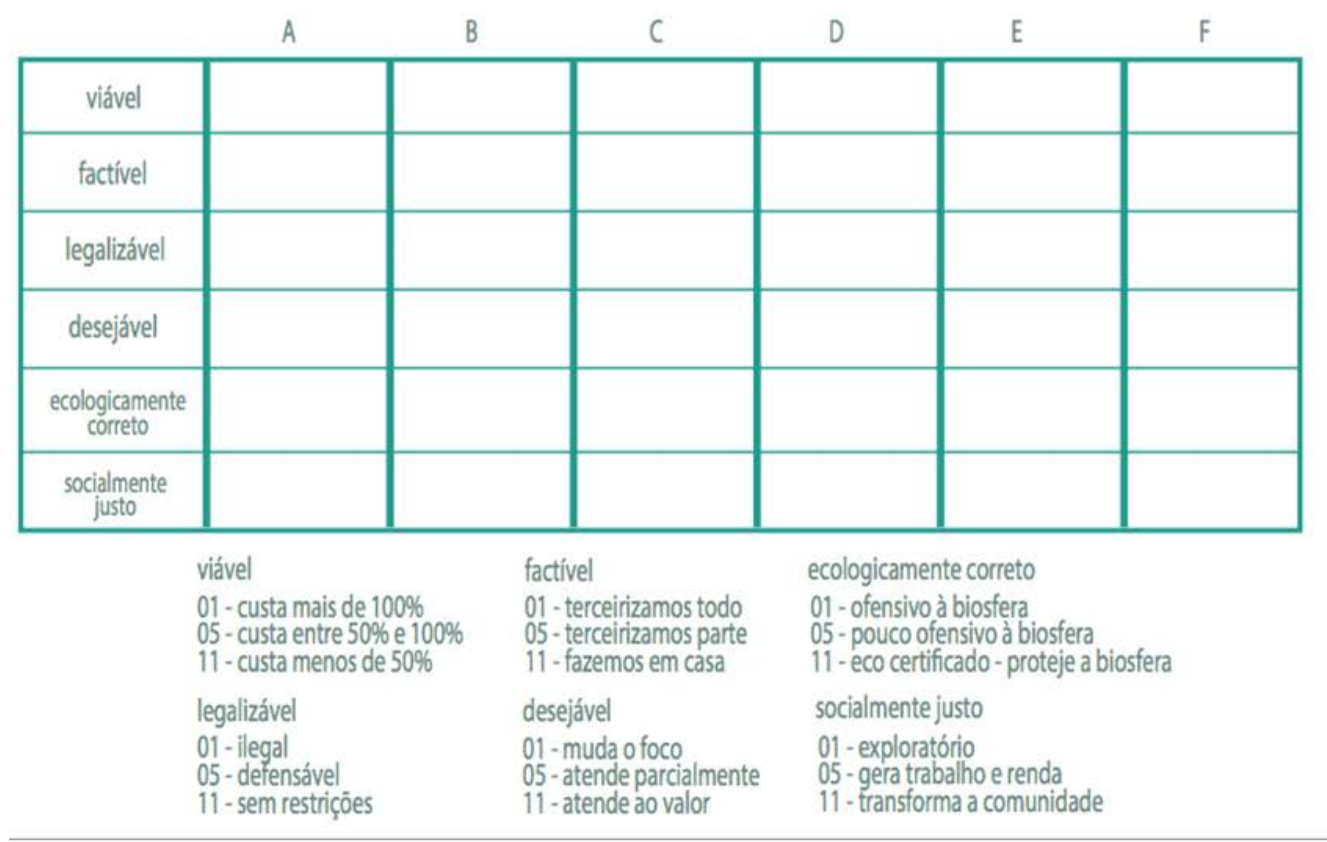

Figura 4 - Fichas de brainwrinting com duas novas heurísticas.

Adaptado de Neves (2014). 


\subsection{Aplicação}

O experimento foi aplicado com estudantes de design da XXX, Portugal, na disciplina de Design de Produto sob o comando do Prof. Dr. Ernesto Vilar. O professor foi responsável pela escolha dos projetos e o experimento foi adaptado ao contexto normal das aulas. Os grupos de estudantes foram acompanhados na aplicação da metodologia e o processo foi registrado através de fotografia e documentação e não houve menção da hipótese da pesquisa para não influenciar os resultados.

Em primeiro momento, os alunos foram orientados a desenvolver puxadores para uma marca italiana de mobiliário infantil, realizando uma leitura e discussão do briefing fornecido pela empresa, que tinha como conceito formas e funções para transformar o quarto das crianças em um lugar lúdico e criativo.

Depois, estes alunos receberam todas as cartas que deveriam ser incluídas no projeto, todas baseadas em pesquisa direta usando a internet como suporte (NEVES et al, 2008). Nós escolhemos para desenvolver todas as cartas das fases de observação e conceituação para ter mais controle sobre a experiência e garantir a conformidade com os parâmetros fornecidos pelas empresas.

Para a etapa de Ideação foi aplicada a técnica de brainwrinting com as cartas desenvolvidas durante a Fase de Observação, que serviram para fornecer informações básicas sobre o projeto. Todas cartas foram dispostas nas respectivas mesas, viradas para baixo, com todos os participantes de cada grupo sentados em volta. Todas as cartas foram lidas e discutidas pelos participantes. Após a discussão, cada aluno teve cinco minutos para preencher uma ideia do quadro A na área superior da ficha, em seguida, cada membro do grupo entregou a sua ficha para o colega do lado direito, em mais uma rodada de cinco minutos. Os alunos foram orientados a ler a ideia do colega e propor uma nova ideia na tabela $B$, em um processo contínuo até que todas as tabelas (de A a F) fossem preenchidas, por todos os grupos. Esse momento de ideação é representado na figura 5:

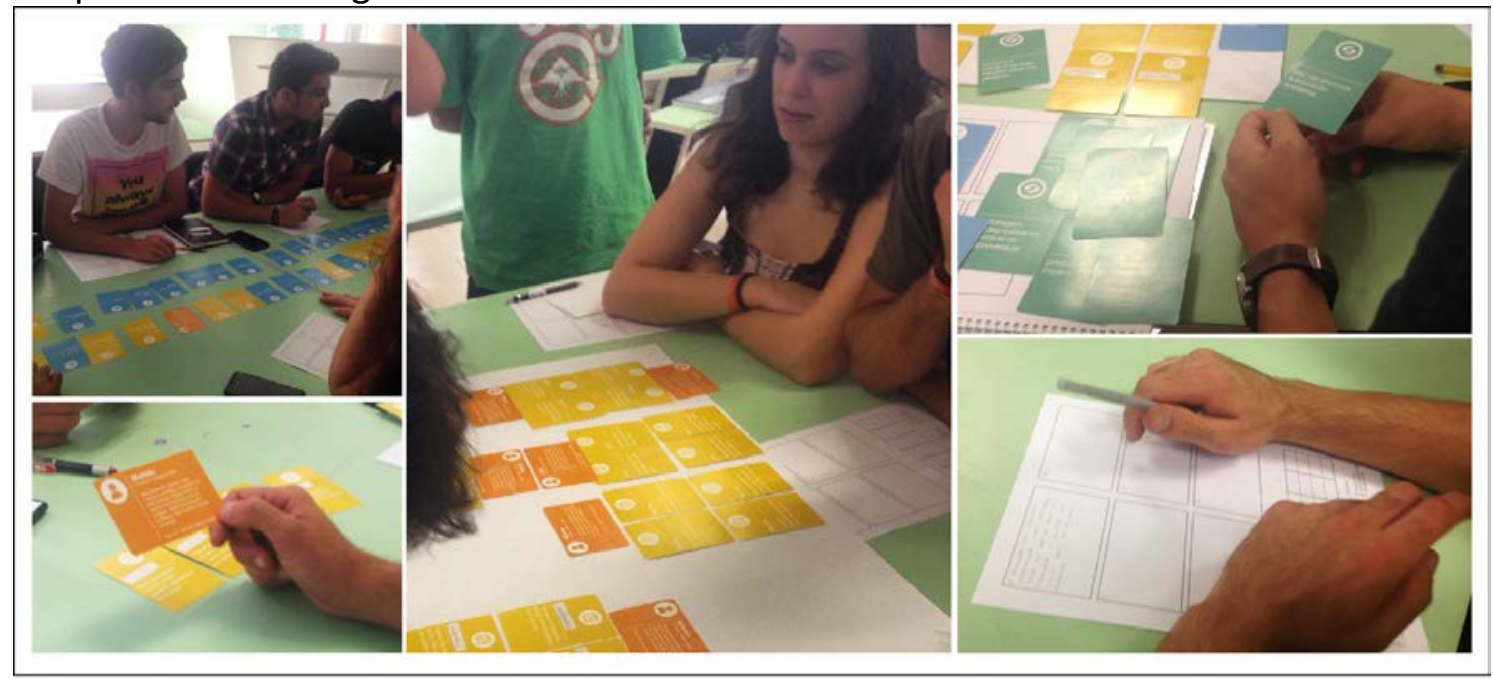

Figura 5 - Ideação por brainwrinting e avaliação das ideias do Projeto 1.

Fonte própria (2015).

Posteriormente os alunos foram orientados a selecionar essas ideias a partir de heurísticas de avaliação na fase de SOLUÇÂO da DTC, também presentes da ficha entregue. 
No segundo projeto os alunos desenvolveram mobiliários urbanos para abrigar antenas de comunicação para uma empresa líder em concepção e fabricação de estruturas para telecomunicações.

Esse segundo projeto teve um grau de complexidade maior em termos de design e serviu para observarmos os alunos desenvolvendo por conta própria as cartas das Fases de Observação e Concepção da DTC e seu comportamento em relação à seleção das ideias com novas heurísticas acrescidas à ficha na fase de Solução.

Novamente na etapa de Ideação foi aplicada a técnica de brainwrinting com as cartas desenvolvidas pelos alunos durante a Fase de Observação. Depois as ideias foram selecionadas a partir de heurísticas de avaliação, presentes da ficha entregue, já com as duas novas heurísticas. Esse segundo momento de ideação é representado abaixo:

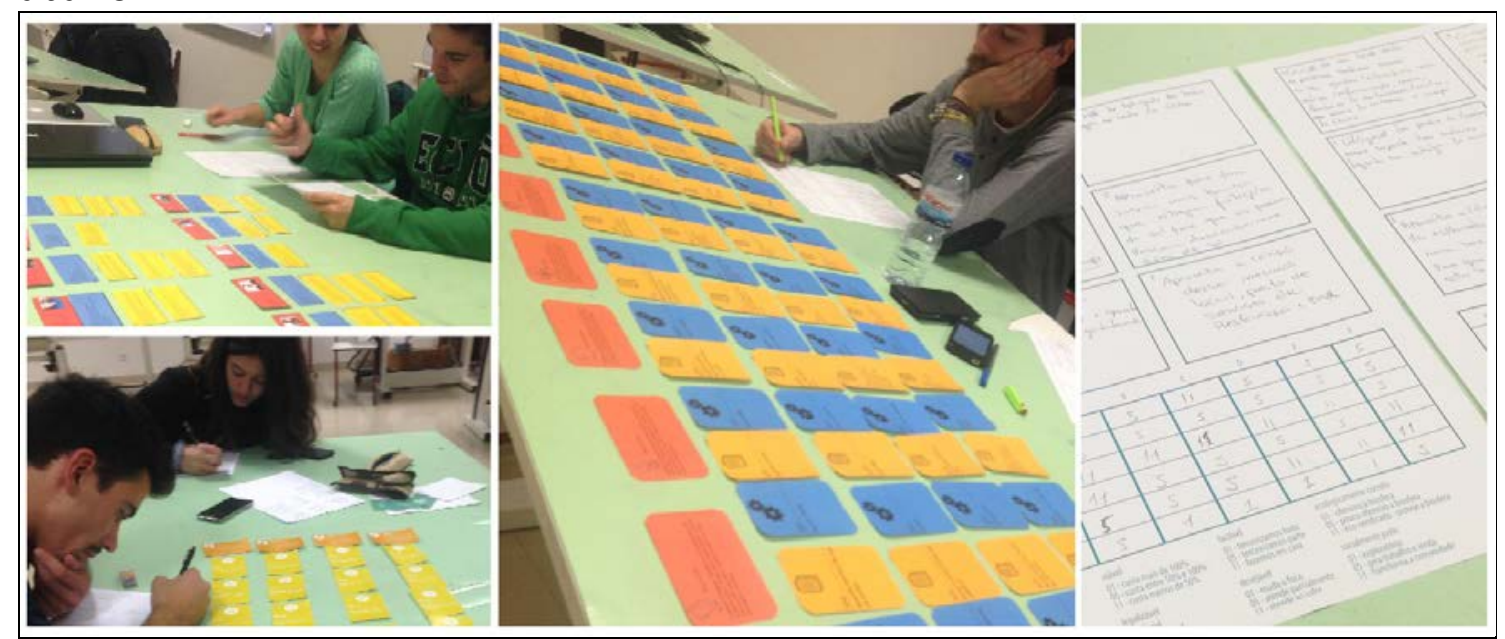

Figura 6 - Ideação por brainwrinting e avaliação das ideias do Projeto 2.

Fonte própria (2015).

O projeto 2, de maior complexidade, serviu para mensurarmos o quantitativo de ideias sustentáveis possivelmente induzidas pelas cartas, além de avaliar se as novas heurísticas adicionadas à ficha aumentariam as chances dos grupos escolherem ideias finais sustentáveis.

\subsection{Resultados}

Os resultados dos projetos mostraram que as cartas com fator verde aparentemente induziram ideais ecológicas. Dizemos aparentemente, pois houve uma interpretação do que os alunos escreveram nas fichas.

Como ideias sustentáveis consideramos aquelas que fizeram menção de valores ou materiais ou processos definidos como fator verde (presentes nas cartas desenvolvidas), como por exemplo: "desenvolvido com PET reciclado"; "com sistema de LED para economizar energia"; "feito de madeira reciclada"; "uso de energia solar"; "sistema de aproveitamento de água da chuva"; entre outros.

Os números se mostraram satisfatórios, uma vez que no Projeto 1, o Grupo 2 (com cartas verdes disfarçadas) obteve um percentual de $20 \%$ de ideias verdes e o Grupo 3 (com cartas verdes explicitas) um percentual de $26 \%$ de ideias mais marcantes quanto a sustentabilidade. 
Já os resultados do Projeto 2 também se mostraram satisfatórios pois de 162 ideias registradas, 64 mencionaram preceitos sustentáveis, um percentual de aproximadamente $40 \%$ de ideias sustentáveis do total.

Cruzando os dados dos dois projetos e considerando os resultados do Projeto 2 como um quarto grupo (Grupo 4) tivemos um aumento considerável no percentual de ideias sustentáveis, como mostra o gráfico de curva de crescimento, a seguir:

\section{Curva de crescimento das ideias sustentáveis}

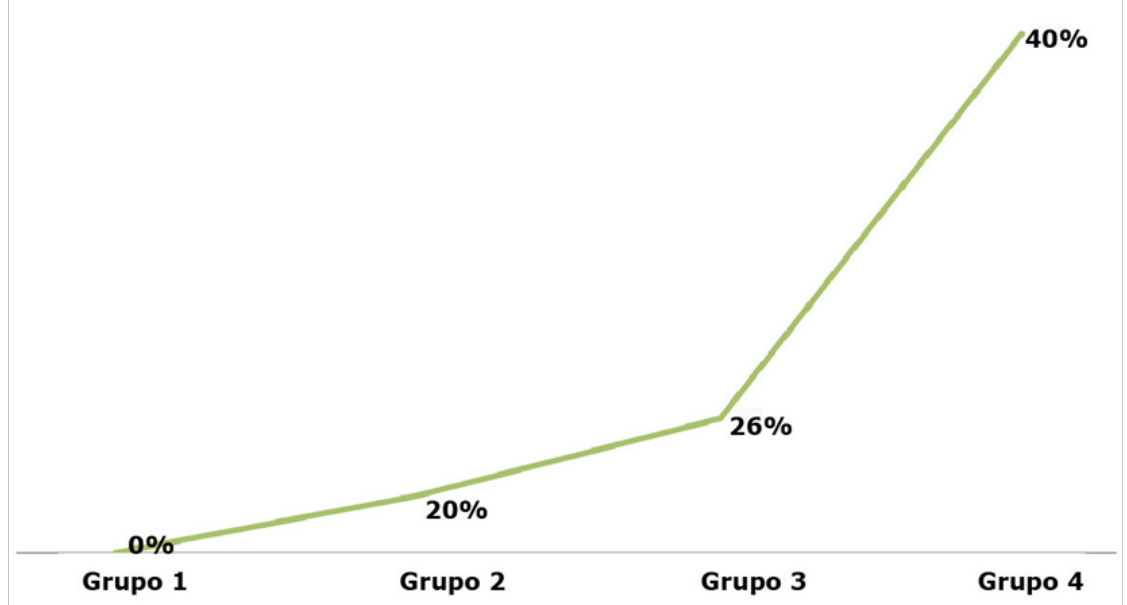

Figura 7 - Curva de crescimento das ideias sustentáveis. Fonte própria (2015).

O Projeto 2 mostrou, ainda, que a inclusão das duas novas heurísticas questionando o aluno sobre a sustentabilidade social e ambiental aparentemente direcionou o olhar para um viés sustentável. Ao observarmos a tabela de avaliação percebemos que todas as ideias selecionadas (com maior pontuação) tinham algum valor sustentável e todos os 10 projetos que seguiram para renderização e especificação técnica, até a data do fechamento da pesquisa, faziam menção de algum valor sustentável.

\section{CONCLUSÃO}

O experimento realizado e seus resultados aparentemente comprovam a hipótese de que fomos capazes de induzir mais ideias sustentáveis a partir da criação de uma nova categoria de cartas com fator verde e acréscimo de duas heurísticas na avaliação das ideias.

Um experimento não é suficiente para afirmar que todos os projetos, de diversas áreas do design, seriam induzidos a mais ideias sustentáveis, mas acreditamos que observar essa possibilidade de indução já abre um caminho válido que pode ser ricamente desdobrado.

Nesse sentido, entendemos que a curto prazo seria preciso aplicar experimentos nas demais fases da metodologia DTC. Como, por exemplo, usar a observação que fizemos sobre o projeto sustentável dando maior ênfase aos materiais e tecnologias e aplicando um experimento de teste na Fase de Configuração, com suporte industrial para a confecção dos produtos e análise de cada etapa do processo. Ou usar a observação que fizemos sobre questão sustentável requerer uma nova estética para "educar" o consumidor e realizar intervenções na Fase de Publicação, 
onde seria possível lançar o produto no mercado e tratar os feedbacks desse consumidor.

É necessário, também, testar o comportamento de indução que geramos através das cartas e heurísticas fora do ambiente acadêmico, como nas equipes de criação das empresas ou dentro de equipes multidisciplinares nas indústrias.

Acreditamos também ser viável transformar as cartas heurísticas e modelo de ficha para ideação em uma ferramenta autônoma para induzir mais ideias sustentáveis durante a fase criativa, que pode ser aplicado independente da metodologia de design escolhida. As cartas, especificamente, podem ser evoluídas para se tornarem uma espécie de "jogo para testar sustentabilidade" de fácil compreensão e aplicação para equipes multidisciplinares e para qualquer projeto de artefato.

Por fim, quando se fala em sustentabilidade é preciso que os designers se mantenham vigilantes e atualizados, pois os impactos causados pelos produtos que desenvolvemos são complexos, múltiplos e, infelizmente, crescentes.

\section{REFERÊNCIAS}

ALVES, Vânia T. Aplicação do Persona Card Game em design de jogos não eletrônicos e estamparia de camisetas. Dissertação (Mestrado em Design) - Universidade Federal de Pernambuco. Recife, 2011.

BEM, Rafael Formiga S. Projeto Ludus: uma metodologia gamificada de gerenciamento de projetos. Dissertação (Mestrado em Design) - Universidade Federal de Pernambuco. Recife, 2014.

BOFF, Leonardo. A Grande Transformação: na economia, na política e na ecologia. Petrópolis, RJ: Vozes, 2014.

BÜRDEK, Bernhard E. História, Teoria e Prática do Design de Produtos. Tradução Freddy Van Camp. São Paulo: Ed. Edgard Blüncher, 2006.

DATSCHEFSKI, Edwin. The Eleven Principles of Total Beauty. Disponível na internet por http em: <http://www.biothinking.com/btintro.htm>. Acesso em 15 maio.2015.

FOOTPRINTNETWORK. Footprint Basics - Overview. Disponível na internet por http em: <http://www.footprintnetwork.org/en/index.php/GFN/page/footprint_basics_ overview/>. Acesso em 13 maio. 2014.

KAZAZIAN, Thierry. Haverá a idade das coisas leves: design e desenvolvimento sustentável. Tradução Eric Roland Rene Heneault. São Paulo: Editora SENAC São Paulo, 2005.

LÖBACH, Bernard. Design industrial: bases para configuração dos produtos industriais. Tradução Freddy Van Camp. São Paulo: Ed. Edgard Blücher, 2001.

MANZINI, Ezio; VEZZOLI, Carlo. O desenvolvimento de produtos sustentáveis: Os requisitos ambientais dos produtos industriais. Tradução Astrid de Carvalho. São Paulo: Editora da Universidade de São Paulo, 2005.

MOTTA, Sérgio Luiz Stirbolov; ROSSI, George Bedinelli. A influência do fator ecológico na decisão de compra de bens de conveniência. São Paulo: Revista de Administração Mackenzie. Ano 2, n.2, (p. 109-130), 2001. 
NEVES, André. Design Thinking Canvas 2.0. Disponível na internet por http em: < https://dl.dropboxusercontent.com/u/1889427/designthinkingcanvasV2.pdf $>$. Acesso em 1 abril.2014.

André; CAMPOS, Fábio; CAMPELLO, Sílvio; CASTILLO, Leonardo; BARROS, Simone; ARAGÃO, Isabella. XDM Métodos Extensíveis de Design. In: P \& D 2008, Anais do Congresso Brasileiro de Pesquisa e Desenvolvimento em Design. São Paulo, 2008.

OLIVEIRA, Bruno. Cards Persona: aplicação da técnica de personas na criação de jogos digitais. Dissertação (Mestrado) - Programa de Pós Graduação em Design, Universidade Federal de Pernambuco, Recife, 2010.

OSTERWALDER, A. Achieve product market fit with our brand new value proposition designer canvas. Disponível na internet por http em:

$<$ http://businessmodelalchemist.com/blog/2012/08/achieve-product-market-fit-withour-brand-new-value-proposition-designer.html. 2012.

PAPANEK, Victor. Design for the real world: human ecology and social change. Second edition. Chicago: Academy Chicago Publichers, 1984.

SACHS, Jeffrey. Introduction to Sustainable Development - Course. Columbia University. Disponível na internet por http em: <https://www.coursera.org/learn/ sustainabledevelopment1>. Acesso em 4 fev. 2015.

VASCONCELOS, L.A.L. Uma investigação em metodologias de design. Trabalho de conclusão de curso (Bacharelado em Design) - Universidade Federal de Pernambuco. Centro de Artes e Comunicação. Design, Recife, 2009.

VEIGA, José Eli da. Desenvolvimento sustentável: o desafio do século XXI. Rio de Janeiro: Garamond, 2008.

VARGAS, Veronica C. L. Uma extensão do Design Thinking Canvas com foco em Modelos de Negócios para a Indústria de Games. Dissertação (Mestrado) Universidade Federal de Pernambuco. Centro de Artes e Comunicação. Design, Recife, 2015.

WALKER, Stuart. Sustainable by design: explorations in theory and practice. Sterling: Earthscan, 2006. 